\title{
BUDGETING BEYOND BUDGETING
}

\author{
Josep M. Rosanas
}




\title{
BUDGETING BEYOND BUDGETING
}

\author{
Josep M. Rosanas ${ }^{1}$
}

\begin{abstract}
While for quite a long time the budget was considered a crucial management tool, it has always been subject to criticism. The criticism has become stronger in the past couple of decades, with an alternative system going by the trade name Beyond Budgeting. In this paper, we review the history and foundations of budgeting to show how, typically, criticism of budgeting has addressed a bad management style and not the technique itself. Then an example is given of how budgeting can be used to a firm's advantage in many fields but mainly so it can avoid unpleasant surprises, create trust between the firm's different hierarchical levels, and enhance learning in the positive sense. This allows the firm to avoid the vicious circles that are often found in budgeting practice because of bad management, not because of the budgets themselves.
\end{abstract}

JEL Classification: M14, M410

Keywords: Budgeting; Management; Trust; Command and control; Management control process

${ }^{1}$ Professor, Accounting and Control, Crèdit Andorrà Chair of Markets, Organizations and Humanism, IESE. 


\section{BUDGETING BEYOND BUDGETING}

\section{Introduction}

Around the middle of the 20th century, the budget was pretty much the management tool. Nevertheless, criticisms of budgeting had already started to emerge, mainly about the time and effort needed to prepare and analyze budgets and about how to balance the different objectives pursued using them. Already in the 21st century and under the name Beyond Budgeting, new proposals to eliminate budgets and replace them with other tools have appeared. Despite this, as we will see, most firms continue to use budgets.

There is a matter that is often neglected in the literature on budgets that is nevertheless crucial. (Both textbooks and academic journals on one side and publications for professionals on the other often ignore it or simply tiptoe around the subject.) It is the matter of how the budgeting process takes place within the control process as well as within the organizational climate and management of the organization, which is crucial in order to obtain good results.

This paper aims to analyze some of the problems related to budgeting. Specifically, it intends to argue that: (1) budgets, when they are used correctly, are very useful and so suppressing them is usually a bad idea; (2) if they are understood as a mere technical tool, then they become a mere bureaucratic requirement void of meaning and even harmful; (3) the way management handles the budgetary process is crucial for the process to go one way or another; (4) an important part of the usefulness of the budgetary process correctly done (subject that has received very little attention in both the academic and professional literature) derives more from its contribution to the human functioning of the organization than from the objective result of budgets (i.e., the documents containing the financial plans); and finally (5) the lessons that budgeting provides are perhaps even more important.

This paper will proceed as follows. First, it will briefly review the history of budgets, to show they are a tool whose use is complex and has many nontechnical aspects, and possibly conflicting objectives that have to be based on a contingency approach. Then the paper will show the typical objections to budgets, analyze them, and go on to give a summary of an example of a particular company's budgetary process. The paper will attempt to show how budgeting can be used correctly in the context of a reasonable structure and management process and how it can be misused to become a sterile routine that goes against its own essence and objectives. Finally, the paper will draw some conclusions, both of a conceptual nature and for business practice. 


\section{Development of Budgeting and Early Criticisms: A Historical View}

Around the middle of the 20th century, budgets were almost the management technique par excellence. Certainly, at the beginning of that century, there were other management techniques. Frederick Winslow Taylor and his followers had created many successful ones under the name "scientific management" but all these techniques were rather "partial," having to do with only one specific activity or one aspect of the firm (in general, of a routine or mechanical kind), with no holistic technique encompassing the firm in its entirety.

As early as 1916, Henri Fayol published "Administration industrielle et générale" ("General and Industrial Administration"), a work that has had a lot of influence in the management literature. (The work was published in French, which made him less known in the English-speaking world until 1949, when a good translation was published.) He established the five elements (or functions) of management - planning, organizing, commanding, coordinating and controlling that later became the basis of organization in most introductory textbooks on administration. He did not use the word "budget" (except only once in the context of public administration budgets) but of course the original French word prévoyance for the first of the five elements, which is often translated as "planning," has a lot to do with budgeting. In fact, we can see that he intended to go well beyond what later on everybody meant as "budgeting," including the way the planning process should take place. The word prévoyance itself (which could have been translated as "forethought") is closer to suggesting (perhaps even more than "planning") that the output of the process should include both a mere forecast of how environmental variables would evolve and, at the same time, an expression of the decisions made by management, which is exactly what a budget should be.

However, the implementation of Fayol's idea did not take place very quickly. According to Hofstede (1968, pp. 20-22), in the United States the use of budgets in private firms started in the 1920s with principles clearly derived from the budget technique used in government. At the same time, they can be seen as a logical extension of Taylor's scientific management. (Fayol, at that time, was largely unknown in the United States.) Large-scale application of budgets started in the 1930s, in the Depression years. In 1941, a detailed survey of companies employing a total of 850,000 people found that roughly 50\% used budgetary control. In 1958, a different sample of 424 companies found that $95 \%$ of them did so. So, the 1950 s were probably the years in which budgets made a lot of progress. In Europe, there was a time lag of about 10 years with respect to the United States (Hofstede, 1968).

So, budgeting was a success story in rather a short time after World War II. A basic accounting textbook that become very popular at the time would state that "Management's primary function is to plan [...] Budgets are the expression, largely in financial terms, of management's plans for operating and financing the enterprise..." (Gordon and Shillinglaw, 1964, chapter 23). In brief, they are the quantitative expression of management's primary function. Many years later, in the 21 st century, the two well-known researchers Hansen and Van der Stede (2004) continued to feel the same way: "Budgeting is an important control system in almost all organizations." Therefore, there is no doubt that budgeting was and still is considered to be an important management tool or procedure. 


\section{Nontechnical Aspects of Budgeting}

Nevertheless, not everybody agreed. From the very beginning, some (positive!) warnings, which were to become criticisms later, appeared. The two landmark managerial (as opposed to merely technical) books that probably contributed more than any others to the dissemination of budgets (Dearden, 1962; Hofstede, 1968) already warned that the task of preparing a good budget and then using it for control purposes was not easy. Calling them "general rules" or "axioms," but in a way that sounds like "grandfather advice," Dearden gives recommendations about how to prepare budgets and who should do it - that the person preparing the initial budget should be the person responsible for operating under it, or that line personnel should be informed of the plans, objectives and timing of the system, that budget personnel should lean over backward to be scrupulously honest with line personnel, and so on (Dearden, 1962, pp. 93-102).

Hofstede (The Game of Budget Control, 1968) gives a long list of recommendations to put budgets into practice as well, and the use of the word "game" in the title already suggests that budgets are not going to be a straightforward technique with no need for judgment. This time, his list comes from a clinical study of a limited number of firms but he recognizes that his recommendations go beyond the strict limits of his findings.

The recommendations embrace all levels of the organization and they are far too long to be summarized here but I will focus on those that are particularly important for the purpose of this paper. For instance, there is a recommendation that is common to all levels of line personnel, from top management to foremen or first-line managers: that the budget system is their tool to manage the company. Consistently, Hofstede tells the controller and budget accountants that the success of a system depends on the line managers, not on themselves, so they must provide assistance and supply the data needed but the actual figuring of the budget has to be done by line managers (Hofstede, 1968, chapter 15). Therefore, budgets are a tool but not merely technical: judgment has to be used by the people that utilize them to make decisions. Hence, using them "correctly" or using them "poorly" will make a lot of a difference in the results because of the different reactions that may be elicited from the line people affected. As we will see below, "lying" or "not lying" in the process and "taking an interest in it" or not depends on the way the budgetary process is designed and implemented.

In other words, budgets have to be considered as a management activity and thus have to be accepted in managerial terms. Budgets should not be expected to be a technique that does not need managerial abilities to be applied or a technique that works alone automatically or is done by specialists in accounting and/or finance. On the contrary, budgeting is something that has to be applied by line management, largely by people whose training in accounting is rather limited, as accounting is not their job (such as people in production or sales, who typically are a big percentage of the firm's payroll) and thus has to be as simple as possible. Otherwise, it would be no surprise to find most of the people involved to be strongly against budgets. They might simply misunderstand budgets or budgets may require an unreasonable effort from them. 


\section{Conflicts in Budgeting Objectives}

However, there is an additional point that is crucial for our purposes. It has to do with the raison d'être of budgets. Why do we do budgets at all? One of the essential reasons for criticism at the top management level has always been the ambiguity in the objective to be attained with budgeting. A cursory examination of the books that covered the subject in the 1960s and 1970s would show that the frequently found expression "budget control" would suggest that control was the primary objective. Since, as stated previously in this paper, budgets were "imported" from public management, the literal translation of them into business practice was about making decisions on how much to spend on every activity or in every department, and then try to explain the possible variances. The main purpose of Fayol (1916) was to foresee what could happen so that, if something considered bad were thought likely to occur, action could be taken to prevent it from happening. This is close to planning but fell short of this concept, which was the next step. Of course, planning and control are two sides of the same coin (Anthony, 1965) and motivation immediately follows. This triple objective (planning, control and motivation) was analyzed explicitly by Barret and Fraser (1977) in some detail, mainly from a practical point of view, showing how there is some degree of conflict between any two of the three objectives. Thus, a budgetary system cannot emphasize all the objectives at the same time: the priorities should be clearly established to avoid conflicts in different and scattered directions. Depending on the firm, on the business environment, on the firm's strategy and (as we will see below) on the critical success factors, it would be wise to emphasize one or more of the three objectives mentioned.

The situation will get more complex if, instead of three objectives, we consider four or more. Many textbooks add "communication" and "coordination," whose degree of importance depends on the degree of centralization or decentralization with which the firm is governed. At a different level of abstraction, other researchers mention as budget objectives "directing management's attention from the present to the future," "enabling managers to anticipate problems in time," "giving managers an ongoing reminder of actions they have agreed to" (Shillinglaw and Meyer, 1983). Hansen and Van der Stede (2002) reexamined the issue of multiple objectives more recently. Obviously, many of these objectives are related to each other but, nevertheless, the fact remains that there may be some degree of conflict.

\section{The "Contingency Approach" to Management Accounting}

An important point in this context is the contingency theory of management accounting (Otley, 1980). This expression, of course, comes from Lawrence and Lorsch (1967), who argued that there is "an important relationship among external variables (the certainty and diversity of the environment, and the strategic environmental issue), internal states of differentiation and integration, and the process of conflict resolution. If an organization's internal states and processes are consistent with external demands, the findings of this study suggest it will be effective in dealing with its environment." Therefore, "managers can no longer be concerned about the one best way to organize" (pp. 156-157).

Vancil (1973) and Anthony, Dearden and Vancil (1972) can be said to have applied that theory to management control systems although they did not use the word "contingency" or cite Lawrence and Lorsch, either in the article or in the book. But what they were saying, in fact, was that, before measures are designed regarding managers' financial responsibility, the strategy and structure of the company must be considered. Not directly mentioning budgeting as such, they

4 - IESE Business School-University of Navarra 
discuss the general design of the control system and emphasize that budgets have to be based on key economic variables: "an effective system is highly situational [...] it must be tailored to the specifics of the situation: this company's objectives, this company's business, and this company's managers" (Anthony et al., 1972, chapter 4).

Furthermore, given the environment, given the product and given the company's strategy, there are "critical success factors" (CSF) on which the control system has to focus. Identifying those factors is not easy, and it may take years of developing a better understanding of the environment and better redefining the company's strategy. "For a management control system to be effective, [...] each characteristic must be thoroughly understood along with its implications for systems effectiveness" and "it must identify the CSFs that should receive careful and continuous management attention if the company is to be successful, and must highlight performance with respect to these key variables in reports to all levels of management" (Anthony et al., 1972, chapter 4). This, of course, includes budgets, considered an essential tool in the management control process, just like they are considered an indispensable part of the primary management function of planning, as indicated in the Gordon and Shillinglaw quote above.

The obvious consequence of the contingency approach (a much better expression than "contingency theory" because, strictly speaking, a contingency theory is no theory at all) and of the multiple objectives of the budgeting system is that both the budgeting techniques and the budgetary process have to be adapted for all these factors. The budgeting process, thus, is of a nontechnical nature and has to be based on the basic management concepts. Therefore, it has to do with the organizational structure and personal interrelationships within the organization. In short, not only is there "no one best way to budget" but also the way to budget in a specific firm at a given point in time depends on many factors, some of them with important elements of subjectivity - namely, the identification of the critical success factors and the strategy that follows as a result.

Subsequent research took a slightly different road, even though the spirit was the same. Thus, Bruns and Waterhouse (1975) showed how there is a clear relationship between organizational structure and the use and behavioral effects of budgets, providing interesting insights into several complex relationships suggested by other research on control in organizations. Flamholtz (1983) examined budgeting practices in the context of a wide concept of management control systems and its relationship with the organizational settings, both in theory and empirically. In any case, budgeting was not seen as a mere technical device but as a practice that had to take place in the context of a strategy and critical success factors and was closely related to behavioral considerations.

\section{Objections to Budgets}

Through the years, many objections to budgets have been formulated, often because of problems that have arisen due to not enough attention being paid to the recommendations of classical books such as those of Dearden and Hofstede. Actual practice in the real world has always been and continues to be very diverse but a trend toward using budgets mechanically and thus inducing different types of gaming has been almost a constant. Two dysfunctional practices along those lines even have a name: ratcheting and storming. Ratcheting consists of management automatically raising quantitative targets (say, sales) when the previous target has been achieved. This practice clashes with the spirit of a reasonable budgeting process but, at the same time, it is easy to predict what is going to happen: objectives will not be achieved to avoid having to face targets that are more difficult in the next period. 
Storming consists of anticipating sales, say, that are supposed to take place in January, recording them under December the previous year, if it looks as if the sales objective is not going to be met, thereby transferring the problem to the next period. This practice has been at the root of many scandals because every year the problem is bound to become bigger and, in the end, fake sales, fake reports or both are the only way to achieve targets. Of course, the opposite may also be done: if it looks like the yearly objectives are going to be met or even surpassed, the recognition of some sales may be delayed to make it easier to meet the next year's targets. In both cases, we get a vicious circle that goes against the company objectives.

Hansen et al. (2003) provide a list of the following problems, taken from Neely et al. (2001):

1. Budgets are time-consuming to put together;

2. Budgets constrain responsiveness and are often a barrier to change;

3. Budgets are rarely strategically focused and often contradictory;

4. Budgets add little value, especially given the time required to prepare them;

5. Budgets concentrate on cost reduction and not value creation;

6. Budgets strengthen vertical command-and-control;

7. Budgets do not reflect the emerging network structures that organizations are adopting;

8. Budgets encourage gaming and perverse behaviors;

9. Budgets are developed and updated too infrequently, usually annually;

10. Budgets are based on unsupported assumptions and guesswork;

11. Budgets reinforce departmental barriers rather than encourage knowledge sharing;

12. Budgets make people feel undervalued.

According to Libby and Lindsay (2010), "some argue that the problems with budgeting stem from the way budgets are used (Horngren et al., 2004) while others argue that budgeting processes are fundamentally flawed (Hope and Fraser, 2003a)." But since the objective of Libby and Lindsay is to present empirical evidence with respect to budgeting practices, they do not analyze in depth the reasons people such as Horngren have to justify their position - which is just what this paper intends to do next.

Let us, then, briefly examine each one of the problems suggested by Hansen et al. (2003) above.

Numbers (1) and (4) have to do with the cost of putting the budgets together and the time to prepare them (which is part of the cost, of course). Naturally, the design of a budgetary system can be made more or less expensive depending on the circumstances but the disproportion between cost and value added indicated by (4), when it happens, responds to a bad design. A good design does not add cost that is not compensated by additional value: simplifying budgeting procedures, when they do not add value, is one of the classical principles expressed by Dearden and Hofstede.

Objections (2), (6), (7), (11) and (12) have to do with the structure and the relationships between people in the organization. But budgets by themselves cannot do such things. It is the people who act in the process who can do them or not. People feel undervalued when their hierarchical superiors make them feel this way, not because of the budget. The way the budgets are drawn up, mainly if this is done mechanically and without the active participation of the hierarchical superiors, may 
indeed make people feel undervalued but, again, this goes directly against the spirit of the classical texts on budgeting. Doing things wrong does not make the tool useless or harmful.

Objection (10), of course, is bad practice. All assumptions have to be supported and, as we will see, budgeting is a good way to learn how to forecast better and how to meet the budgeted figures.

Objections (3), (5) and (9) are particularly bad practice in terms of budgeting: if a budget is not rooted in the critical success factors and the strategy, it will be worse than nothing. If it does not help to create value beyond its cost, a budget should be simplified. And if the business is very dynamic, budgets should be updated as frequently as needed. Anything else is simply bad practice.

A particularly interesting objection is objection (8). This is very often argued but this paper will attempt to show, in an example below, that whether this happens or not depends on how the budgeting process is carried out. Management quality (or the lack of it), and not the budget, is to be blamed if something like this happens.

Therefore, if things are done right, budgets do not have all those problems and so, if they actually do, it must be because of bad management or misuse of the tool. Whether the budget itself pushes organizations into those practices even with good management would be something that would have to be proved by the prosecution, not by the defense.

\section{Beyond Budgeting}

However, since the beginning of the 21st century, the criticism has got worse, both from the consulting world and from the academic world. Of the first group, Jeremy Hope and Robin Fraser have been perhaps the sharpest critics - for instance, in the article "Who Needs Budgets?" (Hope and Fraser, 2003a), whose title already suggests that budgets are useless. The expression "Beyond Budgeting" (Hope and Fraser, 2003b) has been their motto, suggesting that we should go beyond budgeting to something else. In one thing they are absolutely right: budgets cannot solve everything and so often we have to go beyond budgeting but this does not mean that we can dispose of budgets. In other words, budgeting very often may have to be the starting point.

But their criticisms are nothing really new. They go back to the idea that budgets are rigid, help centralization, and are based on a command-and-control approach. And, taking advantage of the trend in favor of the balanced scorecard, they propose a wider set of measures to evaluate performance.

Given today's advances in management tools, indexes that are broader than merely financial numbers may indeed be - and often are - very useful. We have to be careful, though, because there are clear dysfunctional (or even perverse) consequences of performance measures when they are used mechanically and have an incentive payment automatically associated with them (Ridgeway, 1956; Rosanas and Velilla, 2005; Cugueró-Escofet and Rosanas, 2013 and 2016). Hence, eliminating the budget in order to introduce a wider set of performance measures is (a) simply ignoring what budgeting processes can actually achieve, and (b) introducing a new tool that, if misused as budgets are when some of the criticisms above are true, may be even more dangerous than budgeting.

On the academic side, the best-known critic is Michael C. Jensen (2001) but his criticisms are almost exclusively of the incentive systems based on a reward being received if some (budgetary) goal is achieved and nothing if it is not, perhaps with a linear increase beyond the budgeted goal. 
His proposal, basically, is that the reward should be linear from zero - i.e., that the goal should not even exist. The explicit problem of goal-setting (and of the rewards based on such goals) is more general, in fact, and is only indirectly related to the budgetary procedures.

The criticism of Kenneth A. Merchant (2013) are along similar lines, using even stronger words, as can be seen in his title ("Companies Get Budgets All Wrong") but in fact he goes back to the idea that firms need a richer set of performance measures and need to be more flexible.

Empirically and despite the apparent success of the "beyond budgeting" expression and methods, most firms have not discarded their budgeting systems (Libby and Lindsay, 2010). Therefore, the critics' arguments do not seem to have been very convincing, despite all the marketing they have had.

The success they have had (which has been limited, I should add) is to some extent surprising because in their analyses they ignore most of the factors that have been summarized in this paper in relation to the different objectives of budgeting and have focused almost exclusively on the incentive system induced by goal-setting procedures. This is why I want to finish this paper with an analysis of a budgetary system that is useful and that, through an appropriate budgetary process and management style, succeeds in doing the opposite of what the critics argue against.

\section{The Management Control Process}

The classical textbook treatment of the budgetary process is technical, descriptive and quantitatively oriented. It says (mistakenly, sometimes) that the process begins with the marketing people preparing a sales forecast or budget. Mechanically, this seems only logical. Next, the process continues in the different departments with a budget of costs and expenses, given the sales volume and perhaps production volume, and it ends with the controller's department putting everything together in the form of a master budget, which consists mainly of pro forma financial statements. At most, this textbook treatment mentions that there is a "negotiation process" and that sometimes "budgetary slack" is introduced and mentions some of the usual problems found in that area (storming, ratcheting, and so on) merely as problems. Thus, possible negative aspects of the budgetary process are merely implicit.

From an academic point of view, a clear example of the mechanistic approach that agency theory assumes in management control settings can be found in Heinle et al. (2014). In that paper, only two types of budgeting are considered: participative (i.e., bottom-up) or nonparticipative (i.e., top-down). Only extreme possibilities are taken into account: decisions are made either at the top and transmitted down the line or else they are made at the bottom and are accepted by the upper levels. Dialogue and compromise are excluded. The previous attitudes of principal and agent that typically follow their experiences with each other and determine their willingness to cooperate, the organizational climate, the possible identification with the organizational objectives, the atmosphere of trust between them, and many other qualitative and behavioral variables are ignored too, consistent with the basic agency theory model. The management control process, thus, is stylized in what is actually a caricature of what happens in reality: only a sequence of events is described, with no human interaction. No wonder many people want to get rid of it.

Very few cases or textbooks describe real-world budgetary processes, often because, as this paper has argued, they are carried out inappropriately. Doing a budget correctly, using the criteria analyzed above where simplicity is an important one, is a quite difficult endeavor. Next, this 
paper will try to summarize a budget, taken partly from a classic Harvard case, where this is done in some detail, and comment on it. ${ }^{1}$ A parallel example can be found in Vancil (1973, p. 80, "Company C"), although inevitably with some degree of simplification.

\subsection{Critical Success Factors}

First, in terms of the conceptual framework presented above, in order to design a budgetary process the "critical success factors" for the company have to be identified, given the industry and the strategy of the company. In this case, it could be established that, to survive and make a profit, the company essentially has to work for three things: good quality, good service (mainly in terms of delivery) and costs. Glass products are typically for customers that manufacture different types of liquids (all kinds of beverages, chemicals, perfumes, and so on), where the value of the glass receptacle that holds it is small compared with the value of the product itself and they do not want to run the risk of a poor-quality bottle ruining the product. Service (mainly in terms of delivery) is crucial as well. Imagine a producer of soft drinks in the middle of a hot summer: demand increases more than expected, and many bottles are needed to meet this demand. If this is the case, then the glass company has to have flexibility to deliver the glass product when it is needed. For this purpose and given the rigidities of the production process, it needs to have a very accurate sales forecast and production scheduling that can be adapted easily later to meet all the production constraints. Thus, this has to be a high priority of the budgetary process. Inventories are not the solution to the problem: they are expensive to carry and to store (essentially, you carry and store air). As we will see, this can happen only if the budgetary process induces trust between bosses and subordinates.

\subsection{Top Management Involvement}

A second important aspect is the Hofstede principle that top management has to consider the budgets as its tool to run the company, and therefore has to be involved in the process from the very beginning. In the case cited before, the CEO starts the process by asking the divisional managers to submit preliminary estimates of sales and income for the next year, the capital requirements for the same year and an even rougher outlook for the following two years. The divisional managers do not have the time to go through a detailed analysis (which is going to be done only later) and thus they can base their estimates only on their firsthand knowledge of the business. Thus, this small beginning of the budgetary process has already the good characteristic of submitting the management team to an "exam" every year, for which those on the team have to be prepared by knowing their business very well. If they do this, they will get close to the final result of the budgetary process and this will nurture trust between the CEO and the first-line officers.

\subsection{A Nonissue: Participative Budgeting}

Next, a member of the technical staff goes to work in market research, basing this on the available statistics of the evolution of markets and the market trends and climate. This will provide a good check for the "real" sales budget, to be done next by the sales division, and already gives a flavor of what the sales budget may look like at the end of the process.

\footnotetext{
${ }^{1}$ See David F. Hawkins, Empire Glass Company (A), Harvard Business School, case 9-109-043, April 1964 (revised January 2003).
} 
The "real" sales forecast is prepared next using a bottom-up approach - not in a stylized way but with a real dialogue and discussion at the different hierarchical levels. Salespeople know their customers and their needs and can attempt to predict what may happen with them the next year but they may not be familiar with some market trends or the movements of a competitor and so on and may be unnecessarily optimistic or pessimistic.

This point is crucial because, if things are done the wrong way, this may drastically reduce the usefulness of the budgets. Suppose, for instance, that management responds to a forecast from the salespeople by asking systematically for more (not an uncommon practice, certainly). Then it would not be surprising to find that the next year the salespeople understate the amount they think they can sell, which may create a vicious circle where the results are completely unrealistic. Dialogue and negotiation have to result in something that is reasonable and acceptable to both parties. If this does not happen at the end of the process, we may have created a monster for the next period.

Obviously, a "tolerant" management that accepts every proposal from the "bottom" without discussion may create an even worse problem: that of people not making any effort to improve the results. As usual, in Aristotelian terms, the virtue is in the middle. In fact, the budgeting process has to be used: (1) to obtain an accurate sales forecast, which is necessary given production rigidities, and (2) as the instrument to create trust within the sales organizations between the different hierarchical levels. The two elements are crucial, but (1) cannot be achieved without (2). If mistrust takes hold, then we will have all types of gaming behavior like those included in the above criticisms. The attitude of the different levels of management toward their subordinates will be a determining factor in this respect.

The third important aspect is that the participative budgeting issue vanishes in this context: all budgeting has to be participative from the point of view that subordinates have to be listened to, and all budgeting has to be, to some extent, top-down from the point of view of attempting to obtain better goals. The technical study done by marketing research staff may be good for that purpose too, with at least two consequences. First, sometimes the marketing research study will indicate to the line managers that they are perhaps too optimistic: this may happen, for instance, when all customers (producers of soft drinks, for instance) believe that they will gain market share from the others. Then the forecast prepared the line people may be too optimistic, and the market study will indicate that it is impossible for all the customers to have growth of, say, 4\% the next year if the total growth of the industry has been projected at, say, $2 \%$ only. If the optimistic growth forecast never materializes, this will be a clear indication that the line managers engage in ratcheting or a related form of gaming, and trust between bosses and subordinates will go down the drain.

As we mentioned before, in the particular company cited, an accurate sales forecast was crucial for success. Thus, once the discussion had ended, the sales forecast would receive the approval of the top management and would be complete. It would not be modified unless, at the beginning of the period of its execution, it became clear that market circumstances were different from the ones assumed in the budget.

\subsection{Cost and Expense Decisions}

Those in production, so far, had not had a formal role in the budget although, thanks to informal relations, they knew more or less what was going on. After the sales forecast was finished and approved, production plants would prepare: (1) a schedule of production; (2) a standard cost-based statement of direct production costs; and (3) a complete statement of all the fixed costs, including of course committed costs (about which no decision had to be made) and discretionary costs, which 
had to be the result of an always difficult decision. The production plants were considered profit centers, as a consequence of the critical success factors. If the results were not satisfactory, the plants' budgets and primarily the decisions on discretionary costs would have to be revised. Management's objective was not to maximize profit but to obtain a reasonable profit that would satisfy the shareholders. For that purpose, if, in a given year, profit was less than reasonable, the plants would be asked to revise their budgets. Under no circumstances would the sales budgets be revised: if they were considered correct under the assumptions made at the beginning, it made no sense to revise the sales budgets upward, the accuracy of the budgets being a crucial variable.

\subsection{The Role of the Controller}

A fifth issue is the role of the controller. The controller has to be of help in the technical, accounting aspects of the budget, not in filling out the figures. The production people may be very sophisticated engineers but this does not mean that they are able to prepare an income statement appropriately. Nonaccountants tend to mix cash inflows and cash outflows with accruals of different kinds in a meaningless way - for instance, by thinking that today's investments affect this year's income statement or that postponing to next January the payment of some raw materials will increase profit for this year, often forgetting that what is spent under one category of expenses cannot be spent in a different category. Controllers have to help with this, perhaps with forecasting techniques or variance analysis, but they should never produce the numbers of the budget. In the case we are using as an illustration (a conglomerate with many plants), the controller would visit every plant every year for a half a day. He would attempt to make sure they all started with shared hypotheses, see whether the plans that every plant was making were in agreement with the plans of top management, and suggest possible modifications. Those suggested modifications could involve cuts if he thought that the bottom line was insufficient or perhaps (in the opposite direction), taking a long-term view, increased spending on some discretionary costs if the plan could afford it, but the controller would not have the authority to say yes or no to any of the plant's proposals.

Again, participative budgeting is a nonissue, since the information about what is necessary or not and to what extent a plant could benefit from an increase in a discretionary cost is something that by necessity has to come from the plant, while the decision on the bottom line deemed satisfactory has to be made by top management.

\subsection{Putting the Budget Together and Budget Review}

Eventually, at headquarters, and under the direction of the controller, the budgets from every division would be consolidated and the results analyzed. If (again) the bottom line were not good enough, they would send the budget back to the plants so that they could reduce their expenses to meet the target.

Finally, top management would approve the budget.

During the budget's execution, if management saw that some changes had happened in the environment that demanded a change, this change would be made. If this happened toward the end of the year, no change in the budget would be made. Notice that this procedure, poorly used, may induce rigidity but, wisely used, there is no reason why it should do so. A reasonable variance analysis after the fact that takes account of all these possible changes (for better or for worse) can take care of that. 


\section{Discussion: Good Budgeting Requires Good Management, Based on an Optimistic View of Human Beings}

The previous discussion was based on a specific case. In other cases, things may well be different because the critical success factors may well be different too. For instance, in some other cases, the sales effort may be crucial and production scheduling not so much (say, because of the convenience of having enough inventories), so then the budgetary process has to be designed with other objectives in mind and emphasizing other variables, but again with the spirit of achieving something that is worth achieving.

The key point then is the quality of management, in budgeting as in anything else. The quality of good management has to be based on hard evidence (Pfeffer and Sutton, 2006) and on a sense of mission - that is, having as the firm's main objectives those of satisfying customers' needs (real, as opposed to perceived, needs) and employees' real needs (again real, as opposed to perceived, needs). This cannot be done in a purely mechanical way, which is what (implicitly) some academics seem to wish, as seen in the papers quoted.

Sumantra Ghoshal's paper "Bad Management Theories Are Destroying Good Management Practices," published posthumously in 2005, has possibly been his most influential paper. He harshly criticized a "particular ideology" that is "essentially grounded in a set of pessimistic assumptions about both individuals and institutions - a 'gloomy vision' (Hirschman, 1970) that views the primary purpose of social theory as one of solving the "negative problem' of restricting the social costs arising from human imperfections."

These pessimistic assumptions lead to bad management and to the bad practices that were discussed briefly in section 6: the mechanical application of budgets, storming on the part of the "budgetees," ratcheting on the part of management, and so on. It is undeniable that these things happen and therefore that all the criticisms about them are right. But they are not inevitable, if the organization is managed correctly.

In fact, as Ghoshal (2005) and Ghoshal and Moran (1996) have pointed out, the pessimistic assumptions of people being only self-interested and doing only what they think is good for them, may well be a self-fulfilling prophecy. In physics, if we believe that the behavior of, say, quarks is different from what it really is, this belief does not change in any way the behavior of the quarks. In contrast, in management, if we believe people behave a given way, we clearly increase the probability of their behaving that way, for good or bad. If you assume that human beings are going to behave badly (in our case, paying attention only to their own rewards instead of doing what is "good" for the organization), they are likely to end up actually doing that. Pérez López (1991) called this phenomenon "negative learning" and it is something that happens very often in organizations, in a context of a control-and-command management. When no excuses are accepted and the only things management wants to see are measurable results (such as, in the context of budgeting, achieving a sales target or a cut in costs), negative learning often occurs. The firm may end up achieving some short-term objectives but this will be at the cost of making it more difficult for management to achieve the same objectives the next time. Within a control-and-command context, employees learn what they have to do in order to protect themselves from being treated arbitrarily by management. And in a going concern that is supposed to last a long time, perhaps even forever, these practices will not facilitate the desired end. 
Paradoxically, perhaps, budgets and variance analysis should be very useful (it may be their primary objective) in learning about the business, about the organization's capabilities, about what can be expected and the likelihood of the unexpected, and so on. I began by citing Fayol, and I want to go back to him now, because the word he used (prévoyance, or foresight) was intended to reduce surprises or eliminate them altogether. From this point of view, we should carry out budgeting to learn to do so better and avoid undesirable surprises - of course, at a reasonable cost and making it as simple as possible.

\section{Conclusion}

Whether budgeting is a good management tool or not is a pseudoproblem. In any organization, a budget can be useful, even extremely useful, but it has to be done in the context of good management practices, not in the context of a system that is technically perfect on paper but is not understood by the line people involved. It has to be tailor-made, depending on the specific circumstances of the environment and on the company's strategy, and coherent with the company's management style. Many (if not all) of the budgetary systems' shortcomings can be attributed to bad management practices.

Obviously, a budgetary system by itself cannot solve all the decision-making problems of a company, and additional variables may need to be controlled by other means. In other words, we may have to go beyond budgeting often but almost always in the context of a thoughtfully designed budgetary system. 


\section{References}

Anthony, R. N. (1965), Planning and Control Systems: A Framework for Analysis, Boston, Massachusetts: Harvard Business School Press.

Anthony, R. N., Dearden, J., and Vancil, R. F. (1972), Management Control Systems: Text, Cases and Readings, second edition, Homewood, Illinois: Richard D. Irwin.

Barrett, M. E., and Fraser, L. B. (1977), “Conflicting Roles in Budgeting for Operations,” Harvard Business Review, 55(4): July/August.

Bruns, W. J., and Waterhouse, J. H. (1975), "Budgetary Control and Organization Structure," Journal of Accounting Research, 13(2): pp. 177-203.

Cugueró-Escofet, N., and Rosanas, J. M. (2013), "The Just Design and Use of Management Control Systems as Requirements for Goal Congruence," Management Accounting Research, 24(1): pp. 23-40.

Cugueró-Escofet, N., and Rosanas, J. M. (2016, forthcoming), “The Ethics of Metrics: Overcoming the Dysfunctional Effects of Performance Measurements through Justice," Journal of Business Ethics.

Dearden, J. (1962), Cost and Budget Analysis, Englewood Cliffs, New Jersey: Prentice-Hall.

Fayol, H. (1918), Administration industrielle et générale: Prévoyance, organisation, commandement, coordination, contrôle, Paris: H. Dunod et E. Pinot.

Flamholtz, E. G. (1983), “Accounting, Budgeting and Control Systems in Their Organizational Contexts: Theoretical and Empirical Perspectives," Accounting, Organizations and Society, 8: pp. 153-169.

Ghoshal, S. (2005), "Bad Management Theories are Destroying Good Management Practices," Academy of Management Learning and Education, 4(1): pp. 75-91.

Ghoshal, S., and Moran, P. (1996), "Bad for Practice: A Critique of Transaction Cost Theory," Academy of Management Review, 21(1): pp. 13-47.

Gordon, M. J., and Shillinglaw, G. (1964), Accounting: A Management Approach, third edition, Homewood, Illinois: Richard D. Irwin.

Hansen, S. C., Otley, D. T., and Van der Stede, W. A. (2003), "Practical Developments in Budgeting: An Overview and Research Perspective," Journal of Management Accounting Research, 15: pp. 95-116.

Hansen, S. C., and Van der Stede, W. A. (2004), "Multiple Facets of Budgeting: An Exploratory Analysis," Management Accounting Research, 15, pp. 415-439.

Hawkins, David F. (1964), Empire Glass Company (A), Harvard Business School, case 9-109-043, April 1964 (revised January 2003).

Heinle, M. S., Ross, N., and Saouma, R. E. (2014), “A Theory of Participative Budgeting," The Accounting Review, 89(3), pp. 1.025-1.050.

Hirschman, A. 0. (1970), "The search for Paradigms as a Hindrance to Understanding," World Politics, 22(3): pp. 329-343. 
Hofstede, G. H. (1968), The Game of Budget Control, London: Tavistock.

Hope, J., and Fraser, R. (2003a), “Who Needs Budgets?” Harvard Business Review, 81(2): pp. 108-115.

Hope, J., and Fraser, R. (2003b), "New Ways of Setting Rewards: The Beyond Budgeting Model," California Management Review, 45(4) (Summer): pp. 104-119.

Horngren, C. T., Stratton, G. L., Sutton, W. O., and Teall, H. D. (2004), Management Accounting, fourth edition, Toronto: Prentice Hall.

Jensen, M. C. (2001), “Corporate Budgeting is Broken - Let's Fix It,” Harvard Business Review, 79(10): pp. 95-101.

Lawrence, P. R., and Lorsch, J. W. (1967), Organization and Environment, Homewood, Illinois: Richard D. Irwin.

Libby, T., and Lindsay, R. M. (2010), "Beyond Budgeting or Budgeting Reconsidered? A Survey of North American Budgeting Practice," Management Accounting Research, 21(1): pp. 56-75.

Merchant, K. A. (2013), “Companies Get Budgets All Wrong," The Wall Street Journal, www.wsj.com/articles/SB10001424127887323873904578571810482331202, accessed February $11,2016$.

Neely, A., Sutcliff, M. R., and Heyns, H. R. (2001), Driving Value Through Strategic Planning and Budgeting, New York: Accenture.

Otley, D. T. (1980), "The Contingency Theory of Management Accounting: Achievement and Prognosis," Accounting, Organizations and Society, 5(4): pp. 413-428.

Otley, D. T., and Berry, A. J. (1980), "Control, Organization and Accounting," Accounting, Organizations and Society, 5(2): pp. 231-244.

Pérez López, J. A. (1991), Teoría de la acción humana en las organizaciones, Madrid: Ediciones Rialp.

Pfeffer, J., and Sutton, R. I. (2006), Hard Facts, Dangerous Half-Truths, and Total Nonsense: Profiting From Evidence-Based Management, Boston, Massachusetts: Harvard Business School Press.

Ridgway, V. F. (1956), Dysfunctional Consequences of Performance Measurements, Administrative Science Quarterly, 1(2): pp. 240-247.

Rosanas, J. M., and Velilla, M. (2005), "The Ethics of Management Control Systems: Developing Technical and Moral Values," Journal of Business Ethics, 57: pp. 83-96.

Shillinglaw, G., and Meyer, P. E. (1983), Accounting: A Management Approach, seventh edition, Homewood, Illinois: Richard D. Irwin.

Vancil, R. F. (1973), “What Kind of Management Control Do You Need?" Harvard Business Review, 51(2) March-April: pp. 75-86. 